University of Nebraska - Lincoln

DigitalCommons@University of Nebraska - Lincoln

2010

\title{
The Long War and Parental Combat Deployment: Effects on Military Children and At-Home Spouses
}

\author{
Patricia Lester \\ University of California - Los Angeles, plester@mednet.ucla.edu \\ Kris Peterson \\ Madigan Army Medical Center \\ James Reeves \\ Naval Medical Center San Diego \\ Larry Knauss \\ Madigan Army Medical Center \\ Dorie Glover \\ University of California - Los Angeles, dglover@mednet.ucla.edu \\ See next page for additional authors
}

Follow this and additional works at: https://digitalcommons.unl.edu/usnavyresearch

Lester, Patricia; Peterson, Kris; Reeves, James; Knauss, Larry; Glover, Dorie; Mogil, Catherine; Duan, Naihua; Saltzman, William; Pynoos, Robert; Wilt, Katherine; and Beardslee, William, "The Long War and Parental Combat Deployment: Effects on Military Children and At-Home Spouses" (2010). U.S. Navy Research. 38.

https://digitalcommons.unl.edu/usnavyresearch/38

This Article is brought to you for free and open access by the U.S. Department of Defense at DigitalCommons@University of Nebraska - Lincoln. It has been accepted for inclusion in U.S. Navy Research by an authorized administrator of DigitalCommons@University of Nebraska - Lincoln. 


\section{Authors}

Patricia Lester, Kris Peterson, James Reeves, Larry Knauss, Dorie Glover, Catherine Mogil, Naihua Duan, William Saltzman, Robert Pynoos, Katherine Wilt, and William Beardslee 


\title{
The Long War and Parental Combat Deployment: Effects on Military Children and At-Home Spouses
}

\author{
Patricia Lester, M.D., col Kris Peterson, M.D., CDR James Reeves, M.D., \\ Larry Knauss, Ph.D., Dorie Glover, Ph.D., Catherine Mogil, Psy.D., \\ Naihua Duan, Ph.D., William Saltzman, Ph.D., Robert Pynoos, M.D., \\ Katherine Wilt, M.S., William Beardslee, M.D.
}

\begin{abstract}
Objective: Given the growing number of military service members with families and the multiple combat deployments characterizing current war time duties, the impact of deployments on military children requires clarification. Behavioral and emotional adjustment problems were examined in children (aged 6 through 12) of an active duty Army or Marine Corps parent currently deployed (CD) or recently returned (RR) from Afghanistan or Iraq. Method: Children (N = 272) and their at-home civilian (AHC) $(N=163)$ and/or recently returned active duty (AD) parent $(\mathrm{N}=65)$ were interviewed. Child adjustment outcomes were examined in relation to parental psychological distress and months of combat deployment (of the AD) using mixed effects linear models. Results: Parental distress (AHC and AD) and cumulative length of parental combat-related deployments during the child's lifetime independently predicted increased child depression and externalizing symptoms. Although behavioral adjustment and depression levels were comparable to community norms, anxiety was significantly elevated in children in both deployment groups. In contrast, AHC parental distress was greater in those with a CD (vs. RR) spouse. Conclusions: Findings indicate that parental combat deployment has a cumulative effect on children that remains even after the deployed parent returns home, and that is predicted by psychological distress of both the AD and AHC parent. Such data may be informative for screening, prevention, and intervention strategies. J. Am. Acad. Child Adolesc. Psychiatry, 2010;49(4):310-320. Key Words: military children, deployment stress, family risk
\end{abstract}

A $\mathrm{n}$ increasing number of military families in the United States are experiencing repeated cycles of a parent's deployment since the onset of Operation Enduring Freedom (OEF) and Operation Iraqi Freedom (OIF). A parent's departure to fulfill military duties in uncertain and dangerous circumstances, as well as the return and reintegration after deployment, represent significant challenges to children. Some of these challenges may take the form of altered family roles, increased distress in the at-home caretaking (AHC) parent, and the potential impact of combat-related mental health problems in 297 the active duty (AD) parent once he/she returns home. ${ }^{1-3}$ These challenges occur within the context of a heightened sense of danger within the child's multiple ecologies, including family, school, and the military community. Understanding the psychological impact of multiple deployments on military children and parents, both during deployment and after the service member's return, will be important to guide assessments of risk status and to develop appropriate interventions.

Impact of Current Deployment on Children Earlier research among military children and families has been limited to clinical or retrospective samples and was conducted during very different war contexts such as those of Vietnam or Israel. ${ }^{4,5}$ Studies reported some child adjust- 
ment problems during parental deployment included depression, negative behavioral adjustment, and poor academic performance. ${ }^{6-8}$ Children's reactions to parental deployment during Desert Storm operations included increased tearfulness, discipline problems at home, and demands for attention. ${ }^{9}$ Nonetheless, the only longitudinal assessment of children facing parental wartime deployment suggested resiliency among children of military personnel; transient increases in psychological symptoms were documented, but not increased rates of clinically significant elevations compared with community samples. ${ }^{10}$

Although many adapt well, the stress of multiple deployments characterizing current war efforts may begin to take a toll. ${ }^{11-13}$ In the United States, more than 1.2 million children have an AD parent, with more than 700,000 children experiencing one or more parental deployments since September 11, 2001.,14 The cumulative impact of deployment on children and their parents is a particularly salient issue for a professional military at war for a long duration. Research conducted since the initiation of OEF/OIF indicates increased risk for adjustment problems in military children during deployments. ${ }^{15-17}$ Numerous separations may result in a parent being gone for a significant portion of the child's lifespan or at key stages in the child's development. Developmental differences have also been reported. For example, infants and toddlers may be particularly sensitive to caregiver distress, and preschool-aged children may exhibit behaviors that they had previously outgrown. ${ }^{18}$ Preschool-aged children with a deployed parent exhibited higher levels of both internalizing and externalizing behaviors than those without a deployed parent. ${ }^{19}$ School-aged children displayed emotional dysregulation and academic difficulties, and anger and defiance were pronounced in adolescents with a deployed parent. ${ }^{11}$ A recent report indicated higher anxiety in adolescents of deployed parents, with risk increasing as duration of deployment increased. ${ }^{20}$ Ongoing risks include child maltreatment related to deployments, ${ }^{21-23}$ as well as increased marital conflict and domestic violence in families with a deployed parent. ${ }^{24}$

Multiple studies show that child adjustment is influenced by ongoing parental and family functioning throughout development. ${ }^{25-28}$ In military families, prior studies indicate that the mental health of the civilian parent (usually the mother) is highly influential in determining child adjustment. ${ }^{9,10,20,29}$ In addition, some studies indicate that child distress may be influenced by $\mathrm{AD}$ combat-related mental health problems after deployment. ${ }^{9,29-31}$ Such problems, arising from memories of combat-related duties during wartime, subsequent reminders of war experiences, and ongoing anticipation of future deployments, may affect the returning parent's adjustment, including changes in sleep patterns, mood, arousal level, anxieties, and alcohol use, ${ }^{32-34}$ as well as family life and parenting practices. ${ }^{12}$

Studies of the impact of parental combat deployment stress on families to date have several limitations. First, most prior studies primarily examine marital or family functioning ${ }^{35-37}$ but not child functioning specifically. Second, studies evaluating the relationship between parental combat exposure, PTSD and child functioning were typically conducted many years after wartime service, and are largely based on parental rather than child report of symptoms. Third, some studies comprised families living in warexposed countries and may not be applicable to the impact of deployment to a distant war on family members who remain at home. Finally, there are few data on the specific factors that link parental combat exposure to child outcomes, which will be important to guide intervention development.

\section{The Present Study}

This study examines the impact of parental combat deployment and parental distress on the prevalence and severity of behavioral and emotional adjustment problems among school-aged children (aged 6 through 12) of an active duty parent who is currently deployed or recently returned from war-time duties. Conducted at two highly combat-deployed military installations, the aims are to clarify the impact of current versus past parental combat deployments, parental stress, and cumulative duration of parent deployment on child adjustment.

We hypothesized that prevalence and severity of adjustment problems among children of both deployed and returned parents would be a) higher than community norms; b) increased by psychological distress in the AHC and AD parent; and c) increased by the cumulative duration of parental combat deployments during the child's lifetime. 
TABLE 1 Family Characteristics of Study Subjects

\begin{tabular}{|c|c|c|c|}
\hline Demographics & $\begin{array}{l}\text { Recently Returned } \\
\text { (RR) }\end{array}$ & $\begin{array}{l}\text { Currently Deployed } \\
\text { (CD) }\end{array}$ & Total \\
\hline \multicolumn{4}{|l|}{ Families } \\
\hline Families (n) & 118 & 53 & 171 \\
\hline Parent: At-home civilian (AHC) (n) & 111 & 52 & 163 \\
\hline$\%$ Female & $100 \%$ & $100 \%$ & $100 \%$ \\
\hline Mean age (SD) & $32.74(6.7)$ & $34.07(5.3)$ & $33.41(6.4)$ \\
\hline Children $(n)$ & 187 & 85 & 272 \\
\hline$\%$ Female & $44 \%$ & $47 \%$ & $45 \%$ \\
\hline Mean age (SD) & 8.47 (1.9) & $8.68(2.3)$ & $8.53(2.0)$ \\
\hline \multicolumn{4}{|l|}{ Active duty } \\
\hline \multicolumn{4}{|l|}{ Military rank ${ }^{a}$} \\
\hline Enlisted (E 1-E4) & $7.6 \%$ & $9.4 \%$ & $8.2 \%$ \\
\hline NCO (E5-E9) & $66.1 \%$ & $50.9 \%$ & $61.4 \%$ \\
\hline Officer (W1-W5, O1-O6) & $26.3 \%$ & $39.6 \%$ & $30.4 \%$ \\
\hline Mean no. of combat deployments (SD) & $2.09(1.6)$ & $2.16(0.86)$ & $2.11(1.4)$ \\
\hline Mean months combat deployed (SD) & $16.73(7.8)$ & $16.49(8.3)$ & $16.66(8.0)$ \\
\hline
\end{tabular}

\section{METHOD}

\section{Participants}

Population. Between February and October of 2008, a total of 171 families affected by OEF/OIF deployments were recruited for study participation from the Army's Fort Lewis, WA (FL) and the Marine Corps Base Camp Pendleton, CA (CP). Family inclusion criteria consisted of 1) an active duty (AD) parent who was either a) currently deployed (CD) or b) recently returned (RR) from an OEF/OIF combat deployment in the prior 12 months; 2) at least one child between ages 6 and 12 years; and 3) at least one parent (AD or AHC) available for study participation. Exclusion criteria included evidence of severe neuropsychological impairment or psychosis on initial screening; no participants were excluded based on these criteria.

Recruitment Sites. Approximately 5,000 of the 35,000 AD service members at FL had children aged 6 through 12 compared with 3,300 of the $34,000 \mathrm{AD}$ at $\mathrm{CP}$. There were a greater number of Army families $(\mathrm{N}=126)$ than Marine families $(\mathrm{N}=45)$ in the final sample. The mean number of AD deployments for all families in the sample $(\mathrm{M}=2.11)$ was consistent with national and base-specific averages and did not differ across sites. Nationwide, Army deployments are typically 12 months compared with 7 months in duration for the Marine Corps. Accordingly, the FL sample had experienced a greater mean length of total combat-related deployments (17.43 months) compared with CP (14.50 months). AD officers and enlisted in the sample were slightly older (37.3 and 32.7 years, respectively) than national averages for officers and enlisted across military branches (34.6 and 27.1 years, respectively), but mean $\mathrm{AD}$ age did not differ across FL and CP sites. At FL, 26\% of participating families were linked to an officer compared with the overall Army rate of $19.2 \%$ officers. At CP, $42 \%$ of families were linked to an officer compared with an overall Marine rate of $11.8 \%$. The FL site had a greater proportion of RR families (77\% of the total $118 \mathrm{RR}$ ) than the $\mathrm{CP}$ site. CD families ( $\mathrm{N}=53$ ) were more evenly split; 24 of $53 \mathrm{CD}$ families were from the $\mathrm{CP}$ site. Most AD participants (57 of 65 ) were at FL and were male (61 of 65). ADs available to provide data were not CD (always RR). One family had two AD parents and the remaining had one AD parent. Because of the small AD sample, analyses of these parents are limited to exploration of the link between AD parental distress and child outcomes for the total sample (not stratified by deployment status).

Notably, FL and CP families were not significantly different on marital status (97.5\% married), child age $($ mean $[\mathrm{M}]=8.53, \mathrm{SD}=2.0)$, child gender $(45.5 \%$ female), number of deployments experienced per family $(\mathrm{M}=2.11, \mathrm{SD}=1.4)$, $\mathrm{AD}$ age $(\mathrm{M}=33.67, \mathrm{SD}=5.9)$, AHC caretaker age $(\mathrm{M}=33.41, \mathrm{SD}=6.4)$, family income during the previous month, or site differences on any child psychological symptom outcomes. Data from both sites were combined to examine the primary hypotheses comparing child and AHC parent outcomes for those with CD versus RR family members, and post-hoc analyses of significant effects assessed evidence for site-specific differences in outcomes.

Demographics by Deployment Status. From these 171 families, 272 children, 163 AHC and 65 AD parents participated. Table 1 describes demographics, military 
rank, and deployment number and length as a function of deployment status. There were very few enlisted grades 1 to 4 (E1 to E4) ADs, and they were evenly represented across deployment status. In contrast, although commissioned officer (CO)-linked families were a smaller proportion of total families (30.4\%) than noncommissioned officer (NCO)-linked families (61.4\%), a greater percentage of $\mathrm{CO}$ families were CD (40.4\%) relative to NCO families (26.9\%). Combined enlisted parents (E1 to E4 and NCO) had significantly more months of deployment $(17.55, \mathrm{SD}=8.35)$ relative to officers $(14.62, \mathrm{SD}=6.57)(\mathrm{F}(1,170)=5.05, \mathrm{p}=.03)$. Duration of deployment was a covariate in analyses.

\section{Measures}

Demographic factors assessed included age, gender, ethnicity, marital status, military status, and income.

Military factors included site, rank of the AD parent, number of combat deployments, and total months of deployment.

Child outcomes included a) mental health outcomes, as assessed using the Child Behavior Checklist (CBCL), a 118-item parent report measure for ages 6 through 18 years, which includes broadband subscales of internalizing and externalizing symptoms and has solid psychometric properties; ${ }^{38}$ b) child depression, which was measured using the self report short form of the Children's Depression Inventory (CDI), composed of 27 items (this version has been highly correlated with the longer version $[r=0.89]$ and displays acceptable internal consistency, test-retest reliability and validity); ${ }^{39}$ and c) child anxiety, which was assessed using the Multidimensional Anxiety Scale for Children (MASC), a 39-item child report instrument that yields four scale scores and a total score and has shown excellent internal reliability. ${ }^{40}$ Published community norms were used for comparison to study child outcomes.

Parent outcomes included the Brief Symptom Inventory (BSI), a 53-item symptom inventory designed to reflect symptoms of emotional distress across nine dimensions including depression and anxiety. ${ }^{41}$ Convergent validity for the BSI and other standardized scales of symptomatology is good, with both clinical and non-clinical norms available. The scale has good reliability (0.66 to 0.87) and Chronbach's alpha $=0.97$. $\mathrm{AD}$ and AHC posttraumatic stress was assessed using the Posttraumatic Diagnostic Scale (PDS), ${ }^{42}$ which elucidates a traumatic exposure history and reaction rating on a four-point scale. This instrument has good internal consistency (0.92), test-retest reliability (kappa $=0.74$ ) and compares well to clinician ratings obtained in the Structured Clinical Interview for DSM Disorders (SCID, 82\% agreement). In addition, AD completed the Posttraumatic Stress Disorder Checklist-Military, a self-report measure of combat-related PTSD symptoms with 17 Likert-format items. ${ }^{43}$

\section{Procedures}

Study recruitment was done by the UCLA study team in coordination with military Principle Investigators. Military families with a school-aged child were recruited from mailings to housing units at an installation wide level; the recruited sample was not affiliated with a specific unit. Additional recruitment was conducted through flyers at community-based venues such as shopping areas on or near installation sites. Recruitment materials described the purpose of the study ("to assess the impact of parental wartime deployment on school age children") and study eligibility criteria. Study interviewers were BA level and received detailed training in study protocols and emergency procedures, including the recognition of emotional distress, appropriate service referrals, and emergency procedures. Interested individuals responded with a standardized mailing or phone contact. The study coordinator used a standardized recruitment script to ensure that all relevant issues were reviewed.

Of 186 eligible participant families responding, 171 families $(92 \%)$ completed scheduled assessments. Scheduling difficulty was the primary reason for nonparticipation among the 15 eligible families who did not participate. At enrollment, written informed consent was obtained from adults and voluntary assent from children. Recruitment scripts and informed consent described assessments as confidential for participants, except in the case of mandatory reporting requirements. AHC and child participants received a \$20 store card for participation. Institutional Review Board (IRB) approval from UCLA, Madigan Army Medical Center and Naval Medical Center San Diego was obtained for study procedures. All assessments were conducted in the family's home or at a convenient location by family preference. Data were collected from parents (90 minutes) and children (45 minutes) in private interviews using computer-assisted interviewing methodology.

\section{Data Analysis}

To assess the overall impact of parental deployment on child outcomes, prevalence (percentage above clinical cut-off norms) and severity (mean symptoms) of adverse child outcomes were compared across the two deployment groups (CD and RR) using logistic regression for prevalence and analysis of covariance for severity, with age and gender as covariates. Child outcomes were examined in relation to parental psychological distress and months of combat deployment (of the AD) using mixed effects linear models. To avoid potential co-linearity problems (correlations among the predictors), each potential parental distress predictor was examined alone. Final models examined parental distress with and without combat months. In the mixed effects linear model, correlated random effects of multiple children for a single predictor parent score were corrected by including a random effects (family identification code) term with a 
TABLE 2 Child Outcomes by Parent Deployment Status

\begin{tabular}{|c|c|c|c|}
\hline $\begin{array}{l}\text { Child Outcome } \\
\text { Mean (SD) }\end{array}$ & $\begin{array}{l}\text { Recently Returned } \\
N=187 \\
\text { (104 boys, } 83 \text { girls) }\end{array}$ & $\begin{array}{l}\text { Currently } \\
\text { Deployed } \\
N=85 \\
\text { (45 boys, } 40 \text { girls) }\end{array}$ & Norm \\
\hline \multicolumn{4}{|c|}{ Depression (CDI) } \\
\hline Boys & $8.43(6.10)$ & $7.66(6.14)$ & $9.00(7.12)$ \\
\hline Girls & 8.41 (6.79) & $7.23(5.75)$ & $10.76(7.38)$ \\
\hline \multicolumn{4}{|c|}{ Internalizing $(\mathrm{CBCL})^{\mathrm{a}}$} \\
\hline Boys & $46.11(10.17)$ & $46.82(10.15)$ & $46.01(10.36)$ \\
\hline Girls & $42.96(7.75)$ & 45.84 (1 1.71) & $43.61(9.49)$ \\
\hline \multicolumn{4}{|c|}{ Externalizing $(C B C L)^{a}$} \\
\hline Boys & $46.81(10.64)$ & $44.43(9.81)$ & $45.64(10.77)$ \\
\hline Girls & 44.08 (8.77) & $48.45^{\dagger}(11.59)$ & $45.55(10.40)$ \\
\hline \multicolumn{4}{|c|}{ Anxiety (MASC) } \\
\hline Boys & $56.18 * * *(9.13)$ & $56.21 * * *(8.89)$ & $42.06(15.83)$ \\
\hline Girls & $54.79 * * *(9.75)$ & $53.62 * * *(9.68)$ & $49.12(16.05)$ \\
\hline \multicolumn{4}{|c|}{$\begin{array}{l}\text { Note: } C B C L=\text { Child Behavior Checklist; } C D=\text { currently deployed; } C D I=\text { Children's Depression Inventory; MASC = Multidimensional Anxiety Scale for } \\
\text { Children; RR = recently returned. } \\
\text { aMissing data for } C B C L \text { Internalizing and Externalizing. Boys: 94, 40; Girls: 75, 37 (RR, CD). } \\
\text { bMissing data for MASC. Boys: 103, 44; Girls: 81, } 39(R R, C D) . \\
* * * p<.001 ;{ }_{p} p<.10 \text {. }\end{array}$} \\
\hline
\end{tabular}

compound symmetry covariance structure, including the intercept.

\section{RESULTS}

Child Outcomes Compared with Normative Data Overall, children did not show elevations in CDI depression or CBCL internalizing or externalizing symptoms relative to community norms, either as a percentage above clinical cut-offs (prevalence) or, as shown in Table 2, as severity of symptoms (mean scores; CBCL raw scores were analyzed within age and gender categories, but presented as T scores in Table 2). A trend was found $(p=.09)$ for girls with a $\mathrm{CD}$ parent showing elevations in $\mathrm{CBCL}$ externalizing symptoms relative to norms. In contrast to CDI and CBCL outcomes, MASC child anxiety levels were significantly above community norms for both boys and girls, for both deployment groups $(\mathrm{p}<.001)$. MASC anxiety was accounted for primarily by separation anxiety and physical symptoms of anxiety. Figure 1 shows that $31.9 \%$ of

FIGURE 1 Prevalence of clinically significant child symptoms as a function of parent deployment status.

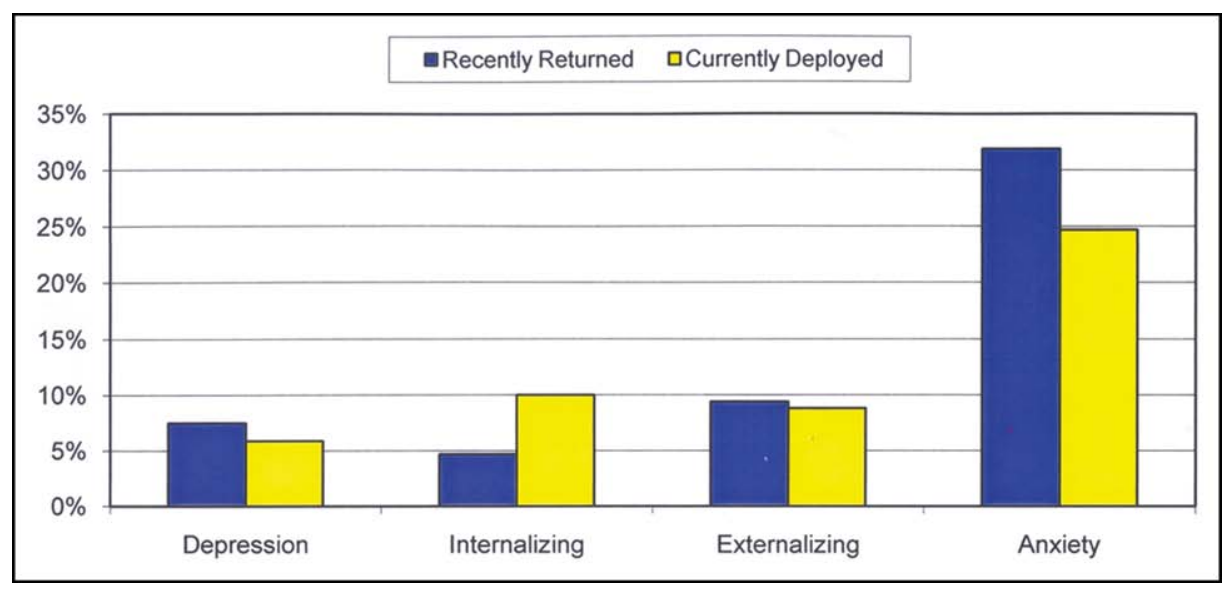


TABLE 3 Outcomes for At-Home Civilian and Active Duty Parents

\begin{tabular}{|c|c|c|c|c|}
\hline \multirow{2}{*}{$\begin{array}{l}\text { Parent Outcomes } \\
\text { Mean (SD) }\end{array}$} & \multirow[t]{2}{*}{$\begin{array}{c}\text { AHC } \\
N=163\end{array}$} & \multicolumn{2}{|c|}{ Community Norms ${ }^{a}$} & \multirow[t]{2}{*}{$\begin{array}{c}A D^{b} \\
N=65\end{array}$} \\
\hline & & BSI Female & BSI Male & \\
\hline Global severity (BSI) & $0.46 * * *(0.40)$ & $0.35(0.37)$ & $0.35(0.37)$ & $0.53 * * *(0.53)$ \\
\hline Depression (BSI) & $0.49 * *(0.55)$ & $0.36(0.56)$ & $0.21(0.33)$ & $0.42 * * *(0.60)$ \\
\hline Anxiety (BSI) & $0.45^{* *}(0.45)$ & $0.34(0.54)$ & $0.26(0.31)$ & $0.54 * * *(0.70)$ \\
\hline \multicolumn{5}{|c|}{$\begin{array}{l}\text { Note: } A D=\text { active duty; } A H C=\text { athome civilian; BSI=Brief Symptom Inventory. } \\
{ }^{a} \text { Community norms are from published BSI manual. }{ }^{41} \\
{ }^{4} A D \text { individuals are all recently returned. } \\
{ }^{* *} p<.01 ;{ }^{* \star *} p<.001 .\end{array}$} \\
\hline
\end{tabular}

the children of a RR parent and $24.7 \%$ of those with a CD parent had clinically significant anxiety symptoms.

Analyses by child age were limited because of uneven sample size and homogeneity of variance violations across age, age by gender, and age by gender by deployment. Analysis of covariance of outcomes as a function of gender and age category (6 through 8 vs. 9 through 12 years) indicated no significant main effects on any child outcomes. Exploratory mixed model analyses, examining child age separately for each gender, indicated that elevations in MASC scores declined with age for females $(\mathrm{t}=-2.00, \mathrm{p}=.05)$ and not males $(\mathrm{t}=$ -.85 ; not significant), but CBCL internalizing scores increased with age for both genders (female: $\mathrm{t}=3.50, \mathrm{p}=.002$; male: $\mathrm{t}=2.02, \mathrm{p}=.05$ ).

Potential Predictors of Child Outcomes Parental Distress. Both AHC (all mothers) and $\mathrm{AD}$ (primarily fathers) had elevated symptoms of global distress, anxiety, and depression relative to community norms (Table 3). Among AD parents, many reported clinically significant symptom levels of global distress $(39.0 \%)$, depression $(30.1 \%)$, and anxiety $(26.4 \%)$. Figure 2 shows the prevalence of clinically significant AHC distress as a function of the spouse's deployment status (RR or CD). Prevalence rates are significantly different across deployment status only for anxiety, indicating greater numbers of cases among AHC with a CD spouse relative to an RR spouse $\left(\chi^{2}=3.93, \mathrm{p}=.04\right)$.

Prevalence of clinical cases on the PDS (severity score of 17 or greater) was strongly influenced by AD rank. Enlisted AD showed significantly more clinical cases than the officer AD group $\left(23.5 \%\right.$ vs. $\left.0 \%, \chi^{2}(1)=3.77, \mathrm{p}=.05\right)$. There was a similar but nonsignificant pattern for more clinical cases among AHC spouses of enlisted AD parents $\left(14.2 \%\right.$ vs. $6 \%$ spouse of officer, $\chi^{2}(1)=$ 2.24, NS). Mean PDS severity scores (AHC: 6.18,

FIGURE 2 Prevalence of clinically significant at-home civilian parent distress as a function of deployment status; Note: PTSS = posttraumatic stress symptoms based on Posttraumatic Stress Disorder Scale (PDS) symptom severity. Anxiety significantly different at $p=.04$.

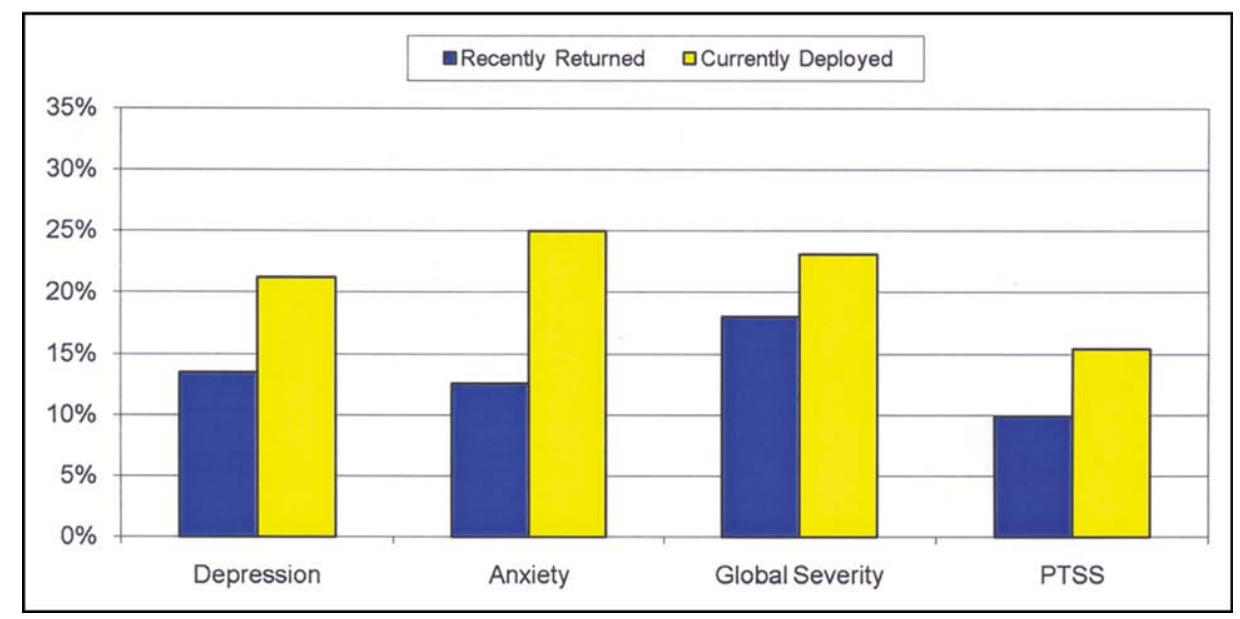


FIGURE 3 Child Behavior Checklist externalizing symptoms as a function of gender and parent deployment status.

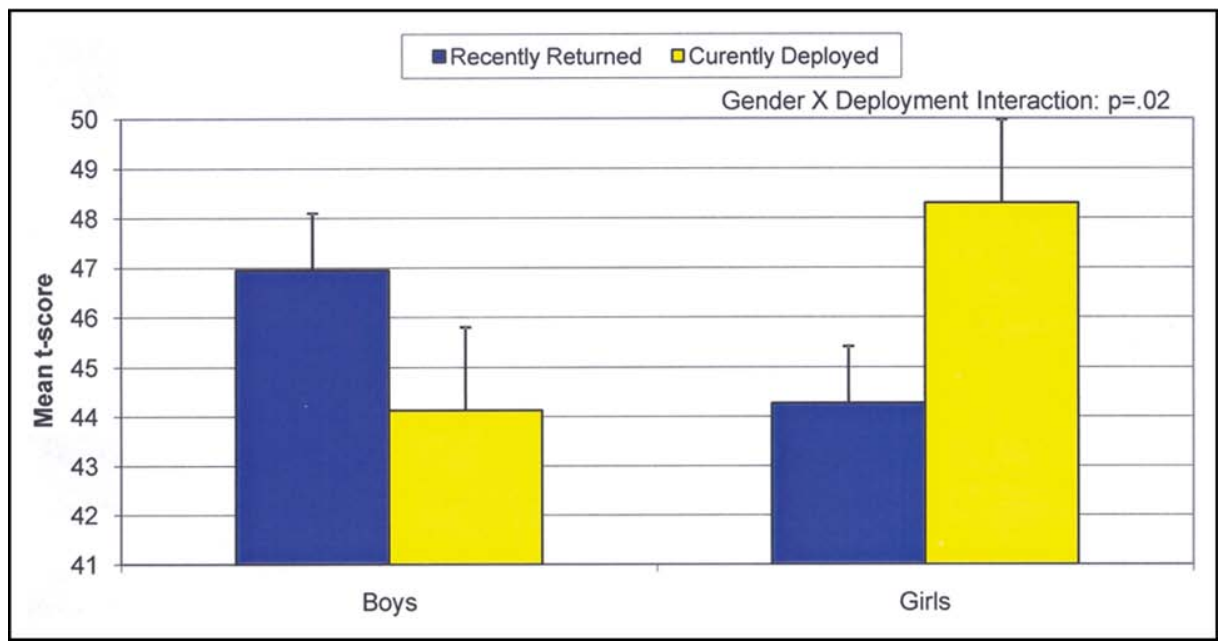

$\mathrm{SD}=9.63 ; \mathrm{AD}: 9.59, \mathrm{SD}=11.25)$ were used in final regression models predicting child distress.

Spouse deployment duration was a significant predictor of $\mathrm{AHC}$ depressive symptoms $(\mathrm{F}(1,162)=$ $7.13, \mathrm{p}=.008)$, global severity distress $(\mathrm{F}(1,162)=$ $6.73, \mathrm{p}=.01)$ and PDS severity $(\mathrm{F}(1,162)=6.38, \mathrm{p}=$ $.01)$; symptoms increased as the number of combat months deployed increased. Deployment duration was not significantly associated with AHC anxiety or any AD outcomes.

AD Parent Deployment Status. No main effect was found for deployment status on child outcomes, but there was a significant effect of deployment $\times$ child gender interaction $(F(1,249)=5.94, p=$ .02) for externalizing symptoms. Girls with a CD parent showed a significantly higher externalizing score than girls with a RR parent, whereas boys showed the opposite pattern (Figure 3). Parameter estimates within each gender indicate that the effect was significant for girls $(p=.03)$ but not for boys $(\mathrm{p}=.15)$.

\section{Final Models for Child Outcomes}

Comparison of adverse child outcomes across the two strata (RR vs. CD) after controlling for age and gender showed no significant differences. However, final models indicated that both combat months and parental distress predicted child outcomes. Mixed effects linear regression models were tested using age and gender as covariates, with parental distress and number of combat months of the $\mathrm{AD}$ parent as predictors of each maladaptive child outcome. Combat months predicted child depression and CBCL externalizing behaviors, but not internalizing behaviors (Table 4). Notably, AHC symptoms strongly predicted CBCL internalizing and externalizing symptoms

TABLE 4 Child Outcomes Predicted by Months of Combat Duty and At-Home Civilian (AHC) Parent Symptoms of Distress

\begin{tabular}{|c|c|c|c|}
\hline Child Outcomes & $\begin{array}{c}\text { Depression (CDI) } \\
n=261\end{array}$ & $\begin{array}{c}\text { Internalizing (CBCL) } \\
n=242\end{array}$ & $\begin{array}{c}\text { Externalizing (CBCL) } \\
n=242\end{array}$ \\
\hline \multicolumn{4}{|l|}{ Parent predictor (predictor $t$ value) } \\
\hline Combat months & $2.46^{*}$ & NS & $3.48 * * *$ \\
\hline \multicolumn{4}{|l|}{ Combat months and: } \\
\hline AHC depression (BSI) & $2.93 * *$ & $5.73 * * *$ & $4.07 * * *$ \\
\hline $\mathrm{AHC}$ anxiety (BSI) & NS & $5.62 * * *$ & $3.63 * * *$ \\
\hline AHC symptom severity (PDS) & NS & $5.33 * * *$ & $5.31 * * *$ \\
\hline
\end{tabular}


TABLE 5 Child Outcomes Predicted by Active-Duty (AD) Parent Symptoms of Distress after Control for Child Age and Gender

\begin{tabular}{|c|c|c|c|}
\hline Child Outcomes & $\begin{array}{l}\text { Depression } \\
\quad(C D I) \\
n=100\end{array}$ & $\begin{array}{c}\text { Internalizing (CBCL) } \\
n=90\end{array}$ & $\begin{array}{l}\text { Externalizing } \\
\qquad \begin{array}{l}(\mathrm{CBCL}) \\
n=90\end{array}\end{array}$ \\
\hline \multicolumn{4}{|l|}{ AD symptoms (predictor $t$ value) } \\
\hline AD depression (BSI) & NS & $4.85^{* *}$ & $2.43^{*}$ \\
\hline AD anxiety (BSI) & NS & $5.62 * *$ & NS \\
\hline AD symptom severity (PDS) & $2.48^{*}$ & $5.33 * *$ & $2.17^{*}$ \\
\hline AD PTSD (PCL) ${ }^{a}$ & NS & NS & $2.07^{*}$ \\
\hline \multicolumn{4}{|c|}{$\begin{array}{l}\text { Note: } B S I=\text { Brief Symptom Inventory; } C B C L=\text { Child Behavior Checklist; } C D I=\text { Children's Depression Inventory; } P C L=\text { Posttraumatic Stress Disorder } \\
\text { Checklist-Military; PDS = Posttraumatic Stress Disorder Scale. } \\
\text { aMissing PCL data resulted in reduced total child: } C D I, C B C L, N=88 . \\
{ }^{*} p<.05 ;{ }^{* *} p<.01 .\end{array}$} \\
\hline
\end{tabular}

even after controlling for cumulative combat months. Child depression was predicted by AHC depression but not combat months. We also examined the relationship between AD distress (for the RR only) and child outcomes. In these analyses (Table 5), AD PTSD symptoms predicted child depression, as well as CBCL internalizing and externalizing behaviors; greater parent symptoms related to greater child symptoms. Child CBCL internalizing behaviors were also strongly predicted by AD depression and anxiety symptoms.

\section{DISCUSSION}

This study compared the prevalence and severity of behavioral and emotional symptoms of schoolaged children and their parents across families with a $C D$ versus $R R$ active duty parent, and examined the potential impact of cumulative deployment duration on outcomes. Children showed considerable resilience as indicated by emotional and behavioral adjustment comparable to published community norms for several standardized measures. However, approximately one-third of the children affected by parental deployments demonstrated clinically significant symptoms of self-reported (MASC) anxiety compared with community norms. Notably, increased child anxiety was not significantly different in children of $C D$ and $R R$ parents. As predicted, psychological symptoms in both $\mathrm{AD}$ and $\mathrm{AHC}$ parents predicted child adjustment problems. Furthermore, the cumulative length of parental deployments during the child's lifetime was associated with increased risk for child depression and CBCL externalizing symptoms.
Thus, the impact of combat deployment on schoolaged children appears to accumulate with increased exposure, consistent with a recent report on parental deployment effects among adolescents. ${ }^{17}$

\section{Predicting Adverse Child Outcomes}

A consistent finding across developmental literature is that children's levels of distress are linked to parental distress. Approximately onethird of the AHC parents and almost $40 \%$ of the smaller subset of AD parents assessed showed elevations in anxiety, depression or global severity scores, comparable to or higher than other retuning service members from OIF/OEF and their spouses. $^{44,45}$ This study's rates of AD service members screening positive for PTSD after combat deployments are comparable to previously reported studies on Iraq war veterans. ${ }^{44}$ The level of distress among service members and their partners clearly underscores the family level risk for operational wear and tear.

Past studies of the impact of parental deployment on children generally index adverse child outcomes at a single point in time and often assume that the most difficult time for the child is during the parent's absence. The current study suggests that children can have complex reactions to multiple phases of the deployment cycle, as evidenced by high levels of child anxiety even after the active duty parent has returned. As the number of deployments increase along with the total amount of time a parent is absent, there is a greater likelihood for AD combat operational stress, changes in parenting styles, emotional estrangement, or even heightened fear between family members. ${ }^{31}$ The relative timing of parental 
departure and return represents variable challenges for children and families, as described in a deployment cycle model. ${ }^{46}$ Further studies are needed to assess child adjustment and develop interventions across phases of this cycle.

Results indicate that school-aged boys and girls have different behavioral reactions during and after a deployment. Girls, and not boys, showed increased externalizing symptoms when a parent was deployed compared with when the parent was returned. In contrast, boys may have more difficulties adjusting to reduced autonomy and increased structure when the deployed parent returns. Findings here differed as a function of gender, age, and symptom reporter (age effects on CBCL parent report vs. MASC child report). Longitudinal studies are sparse; however, such factors are all likely to influence the long-term impact of wartime deployments on child outcomes and warrant further investigation.

Whereas child distress was not lower in the $\mathrm{RR}$ relative to the CD group, AHC parent distress was lower in those with an RR spouse than in those with a CD spouse. Anecdotal reports suggest the deployed spouse's return generally heralds a net decrease in the nondeployed spouses stress burden and a net increase in support. Civilian parents with a deployed spouse manage multiple increased duties, including financial, child care, and household responsibilities with an often limited support system, which may contribute to increased distress during deployment separations. Nevertheless, the fact that AHC parent distress increased as their spouses' total number of months deployed rose, mirroring the pattern seen in children, suggests cumulative stress builds across wartime deployments for children and civilian parents.

AD officers reported few PTSD symptoms, and none met criteria for PTSD, whereas 23\% of enlisted AD parents screened positive for PTSD. While all participants were aware of the confidential nature of study participation, this rank difference may represent a reporting bias, with $\mathrm{AD}$ officers less likely to endorse psychological symptoms because of potential career impact. A similar nonsignificant pattern was seen among the athome caretaker spouses of officers compared with enlisted service members. Future studies will need to examine the specific military and socio-economic components of rank that contribute to differential prevalence rates at the parent level as well as the potential for child level influences.
A consistent finding across developmental literature is that child distress is linked to parental distress. Multiple pathways are theorized by which parental psychological distress levels can have an impact on children, through impairments in primary caretaking behaviors such as maintaining emotional availability and consistent care routines. The current analyses of parental predictors of adverse child outcomes support this relationship in military families, with parental psychological symptoms linked to a range of child emotional and behavioral symptoms. Because the study design was cross-sectional, we are not able to determine whether there is a reciprocal influence of child distress on parental distress for this sample. Longitudinal evaluation of child and family adjustment across the cycles of deployment are needed to determine the directionality of these influences. Nevertheless, this study contributes a unique observation in the current literature in trying to isolate the relationships between specific adverse child outcomes and specific symptom presentations in $\mathrm{AD}$ and AHC parents. Such pathways provide guidance to targeting interventions that will best support family resiliency and address family distress in the context of wartime deployments.

Traditional methods of teaching emotional regulation skills, using family level anxiety management approaches and enhancing family communication require adaptation to address the specific worries of children of combat-deployed parents. Whereas the implications of heightened separation anxiety symptoms in a population affected by parental wartime deployments may be distinct from similar symptoms in a general child population, ${ }^{47}$ the presence of persistent anxiety symptoms may interfere with important child developmental tasks and family life (such as independent sleeping, school attendance, etc.). Clinical experience with these children suggests heightened anxiety about another potential deployment even after a parent has returned. Families often report that children are reactive to reminders of separation, and especially to cues that may indicate a service member's potential departure, such as donning a uniform or coming home late from work. In addition, parents often report children's worries about parental safety and possible loss of the military and civilian parents, with a persistent sense of uncertainty about life-threatening danger. Reintegration may also be marked by a child's fears over changes in 
their parent, whether behavioral or physical. ${ }^{31}$ Developing skills that enable both parents and children to reduce psychological distress, as well as to negotiate the ambiguity of a parent's presence and absence, may assist families with adjustment across the deployment cycle. ${ }^{48}$

There are two primary limitations to the present study. First, this is a convenience sample recruited from families living on or near large military installations. The generalizability of any data set is dependent on how it is collected; there may be biases introduced by the recruitment process. For example, participating families may have been more pro-social or had greater financial need for the assessment incentive than those who refused. However, the demographics of the recruited sample at both sites was composed almost entirely of married families, with a mean parental age of early 30 's, and consisting of more officers at both sites than officer-to-enlisted ratios reported for the Army or the Marines. Given that officers and their spouses reported less psychological distress than the enlisted individuals and their spouses, this study sample may reflect lower risk than the overall population of deployed service member parents, and may actually underestimate overall risk for emotional distress in these families. Conversely, this volunteer sample of families interested in participating in this study may have been more likely to report symptoms and seek services. Several of the key findings are similar to those in a much larger sample of adolescent children and their parents, ${ }^{20}$ suggesting that findings here may be consistent across other military families.

Secondly, this is a cross-sectional analysis of families currently deployed and those recently returned. Whereas it is logically plausible that the emotional distress or problem behaviors of a child can increase parental distress and that distress may be reciprocal across family relationships, we believe that the directionality of the hypothesized "predictors" is more reasonable; the duration of parental combat deployments during the child's lifetime and current reports of parental distress symptoms increase child symptoms. In any case, these data indicate increased risk for emotional distress across the family system. Future studies

\section{REFERENCES}

1. McFarlane AC. Military deployment: the impact on children and family adjustment and the need for care. Curr Opin Psychiatry. 2009:22:369-373

2. Bowling UB, Sherman MD. Welcoming them home: Supporting service members and their families in navigating the tasks of reintegration. Prof Psychol Res Pr 2008;39:451-458. should be designed to provide longitudinal information regarding family adjustment across the deployment cycle, and to clarify the timing of adjustment across the phases of deployment and reintegration.

The military demographic in the United States has changed in the past several decades to include a much larger proportion of service members having families. Planning for extended military operations needs to take into account the impact on family members. Programs that potentially mitigate the impact as described here need to be examined for benefit in an effort to offset these consequences. By demonstrating the impact of wartime deployments across the family system, as well as by providing information about the relationships among family member's stress, these findings provide support for a family-centered, targeted preventive approach for children and families facing ongoing combat-related deployments, and especially interventions that target reduction of parental anxiety, depression and posttraumatic stress symptoms, as well as child anxiety symptoms. \&

Accepted January 15, 2010

Drs. Lester, Glover, Mogil, Saltzman, and Pynoos, and Ms. Wilt are with UCLA Semel Institute for Neuroscience and Human Behavior. Drs. Peterson and Knauss are with Madigan Army Medical Center. Dr. Reeves is with the Naval Medical Center San Diego. Dr. Duan is with Columbia University. Dr. Beardslee is with Children's Hospital Boston, Harvard Medical School

This study was supported by a grant from the National Institute for Child and Human Development (RO3 HD049451).

The views expressed are those of the author(s) and do not reflect the official policy of the Department of the Army, the Department of Defense, or the U.S. Government. The investigators have adhered to the policies for protection of human subjects as prescribed in 45 CFR 46.

The authors acknowledge and express thanks for the dedication of Christian Geye and the families at Fort Lewis and Marine Corps Base Camp Pendleton for their generous participation in this study.

Disclosure: Drs. Lester, Peterson, Reeves, Knauss, Glover, Mogil, Duan, Saltzman, Pynoos, and Beardslee, and Ms. Wilt report no biomedical financial interests or potential conflicts of interest.

Correspondence to Dr. Patricia Lester, Department of Psychiatry \& Biobehavioral Sciences, UCLA Semel Institute, 760 Westwood Plaza, Room A8-159, Los Angeles, CA 90024; e-mail: plester@ mednet.ucla.edu

0890-8567/10/(C2010 American Academy of Child and Adolescent Psychiatry

DOI: $10.1016 /$ i.jaac. 2010.01 .003

3. McNulty PAF. Reported stressors and health care needs of active duty navy personnel during three phases of deployment in support of the war in Iraq. Mil Med. 2005;170:530535

4. Johnson SJ, Sherman MD, Hoffman JS, et al. The psychological needs of US military service members and their families: a 
preliminary report. Washington, DC: American Psychological Association; 2007.

5. Cozza SJ, Chun RS, Polo JA. Military families and children during operation Iraqi freedom. Psychiatr Q. 2005;76:371-378.

6. Hiew CC. Separated by their work: families with fathers living apart. Environ Behav. 1992;24:206-225.

7. Levai M, Kaplan S, Ackermann R, Hammock M. The effect of father absence on the psychiatric hospitalization of navy children. Mil Med. 1995;160:104-106.

8. Yeatman GW. Paternal separation and the military dependent child. Mil Med. 1981;146:320-322.

9. Rosen LN, Teitelbaum JM, Westhuis DJ. Children's reactions to the Desert Storm deployment: initial findings from a survey of Army families. Mil Med. 1993;158:465-469.

10. Jensen PS, Martin D, Watanabe H. Children's response to parental separation during Operation Desert Storm. J Am Acad Child Adolesc Psychiatry. 1996;35;433-441.

11. Lincoln A, Swift E, Shorteno-Fraser M. Psychological adjustment and treatment of children and families with parents deployed in military combat. J Clin Psychol. 2008;64:984-992.

12. Palmer C. A theory of risk and resilience factors in military families. Mil Psychol. 2008;20:205-217.

13. Waldrep DA, Cozza SJ, Chun RS. The impact of deployment on the military family. In: The National Center for Post Traumatic Stress Disorder, ed. The Iraq War Clinician Guide. 2nd ed Washington, D.C.: Department of Veterans Affairs; 2004:83-86.

14. Kelley ML, Finkel LB, Ashby J. Geographic mobility, family, and maternal variables as related to the psychosocial adjustment of military children. Mil Med. 2003;168:1019-1024.

15. Huebner AJ, Mancini JA, Wilcox RM, Grass GA, Grass SR Parental deployment and youth in military families: Exploring uncertainty and ambiguous loss. Fam Relat. 2007;56:112-122.

16. Flake EM, Davis BE, Johnson PL, Middleton LS. The psychosocial effects of deployment on military children. J Dev Behav Pediatr. 2009;30:271-278.

17. Chandra A, Burns RM, Tanielian TL, et al. Understanding the impact of deployment on children and families: findings from a pilot study of Operation Purple Camp participants. Santa Monica, CA: RAND; 2008

18. Murray JS. Helping children cope with separation during war. J Spec Pediatr Nurs. 2002;7:127-130.

19. Chartrand MM, Frank DA, White LF, Shope TR. Effect of parents' wartime deployment on the behavior of young children in military families. Arch Pediatr Adolesc Med. 2008;162:1009-1014.

20. Chandra A, Lara-Cinisomo S, Jaycox LH, et al. Children on the homefront: the experience of children from military families. Pediatrics. 2010;125:13-22.

21. Rentz ED, Marshall SW, Loomis D, Casteel C, Martin SL, Gibbs DA. Effect of deployment on the occurrence of child maltreatment in military and nonmilitary families. Am J Epidemiol. 2007;165 1199-206.

22. Gibbs DA, Martin SL, Kupper LL, Johnson RE. Child maltreatment in enlisted soldiers' families during combat-related deployments. J Am Med Assoc. 2007;298:528-535.

23. McCarroll JE, Fan Z, Newby JH, Ursano RJ. Trends in US army child maltreatment reports: 1990-2004. Child Abuse Rev. 2008;17: 108-118.

24. McCarroll JE, Ursano RJ, Liu X, et al. Deployment and the probability of spousal aggression by U.S. Army soldiers. Mil Med. 2000;165:41-44.

25. Rutter M, Quinton D. Parental psychiatric disorder: Effects on children. Psychol Med. 1984;14:853-880.

26. Beardslee WR. Familial influences in childhood depression. Pediatr Ann. 1984;13:32-36.

27. Christ GH, Siegel K, Sperber D. Impact of parental terminal cancer on adolescents. Am J Orthopsychiatry. 1994;64:604-613.
28. Lester P, Stein JA, Bursch B. Developmental predictors of somatic symptoms in adolescents of parents with HIV: a 12-month follow-up. J Dev Behav Pediatr. 2003;24:242-250.

29. Medway FJ, Davis KE, Cafferty TP, Chappell KD. Family disruption and adult attachment correlates of spouse and child reactions to separation and reunion due to operation desert storm. J Soc Clin Psychol. 1995;14:97-118.

30. Klarić M, Francisković T, Klarić B, et al. Psychological problems in children of war veterans with posttraumatic stress disorder in Bosnia and Herzegovina: cross-sectional study. Croat Med J. 2008;49:491-498.

31. Sayers SL, Farrow VA, Ross J, Oslin DW. Family problems among recently returned military veterans referred for a mental health evaluation. J Clin Psychiatry. 2009;70:163-170.

32. Steindl SR, Young RM, Creamer M, Crompton D. Hazardous alcohol use and treatment outcome in male combat veterans with posttraumatic stress disorder. J Trauma Stress. 2003;16:27-34.

33. McFall ME, Mackay PW, Donovan DM. Combat-related posttraumatic stress disorder and severity of substance abuse in Vietnam veterans. J Stud Alcohol. 1992;53:357-363.

34. Shalev AY, Freedman S, Peri T, et al. Prospective study of posttraumatic stress disorder and depression following trauma. Am J Psychiatry. 1998;155:630-637.

35. Caselli LT, Motta RW. The effect of PTSD and combat level on Vietnam veterans' perceptions of child behavior and marital adjustment. J Clin Psychol. 1995;51:4-12

36. Jordan BK, Marmar CR, Fairbank JA, et al. Problems in families of male Vietnam veterans with posttraumatic stress disorder. J Consult Clin Psychol. 1992;60:916-926.

37. Maloney LJ. Post traumatic stresses on women partners of Vietnam veterans. Smith Coll Stud Soc Work. 1988;58:122-143.

38. Achenbach TM. Manual for the Child Behavior Checklist/4-18 and 1991 profile. Burlington, VT: University of Vermont; 1991.

39. Kovacs M. Rating scales to assess depression in school-aged children. Acta Paedopsychiatr. 1981;46:305-315.

40. March JS, Parker JD, Sullivan $\mathrm{K}$, et al. The Multidimensional Anxiety Scale for Children (MASC): Factor structure, reliability, and validity. J Am Acad Child Adolesc Psychiatry. 1997;36:554565

41. Derogatis LR, Melisaratos N. The Brief Symptom Inventory: an introductory report. Psychol Med. 1983;13:595-605.

42. Foa EB, Cashman L, Jaycox L, Perry K. The validation of a self-report measure of posttraumatic stress disorder: The posttraumatic diagnostic scale. Psychol Assess. 1997;9:445-51.

43. Weathers FW, Huska JA, Keane TM. PCL-M for DSM-IV. Boston: National Center for PTSD, Behavioral Science Division; 1991.

44. Milliken CS, Auchterlonie JL, Hoge CW. Longitudinal assessment of mental health problems among active and reserve component soldiers returning from the Iraq war. J Am Med Assoc. 2007;298: 2141-2148.

45. Eaton KM, Hoge CW, Messer SC, et al. Prevalence of mental health problems, treatment need, and barriers to care among primary care-seeking spouses of military service members involved in Iraq and Afghanistan deployments. Mil Med. 2008;173: 1051-1056.

46. Pincus SH, House R, Christenson J, Adler LE. The emotional cycle of deployment: a military family perspective. US Army Med Dep J. 2001:615-623.

47. Hoven CW, Duarte CS, Lucas CP, et al. Psychopathology among New York City public school children 6 months after September 11. Arch Gen Psychiatry. 2005;62:545-552.

48. Faber AJ, Willerton E, Clymer SR, MacDermid SM, Weiss HM. Ambiguous absence, ambiguous presence: A qualitative study of military reserve families in wartime. J Fam Psychol. 2008;22:222230. 